\title{
A STREAMLINED ANAESTHETIC SYSTEM
}

\author{
J.A. BAIN, M.D., C.R.C.P. (C) AND W.E. SPOEREL, M.D., F.R.C.P.(C)"
}

SURGICAl PROCEDUREs about the head and neck require an anaesthetic system which is light in weight, does not create facial distortion and does not cause excessive drag on the endotracheal tube, (Figure I). The most popular single limb system employed for adults is the Magill attachment or Mapleson $A^{1}$ (Figure 2) and for children a variation of the Mapleson D system, particularly the arrangement described by Rees ${ }^{2}$ (Figure 3). The disadvantage of the Mapleson A system is that it has a relatively heavy weight pop-off valve located close to the patient's face, which usually becomes buried under the sterile draps, leaving the anaesthetist in an awkward position to adjust the tension of this valve. The currently manufactured Rees modification of system $D$ is useful only for paediatric anaesthesia. With these disadvantages in mind and the desire for a single limb system which could have pollution control incorporated, a streamlined modification combining the Mapleson $\mathrm{D}$ and $\mathrm{E}$ systems was constructed.

\section{Description}

Figure 4 illustrates the modified system. The fresh gas inflow tubing is incorporated inside the exhalation limb of the system. This decreases the bulk of the system and the additional drag of a second tube running to the patient's face. The system is constructed out of light weight plastic, the diameter being uniform and approximately $22 \mathrm{~mm}$. The attachments are 60 ins. to 72 ins. in length with an internal volume of about $500 \mathrm{cc}$ (about $85 \mathrm{ml} /$ foot of tubing). The patient end of the attachment has an internal diameter of $15 \mathrm{~mm}$ adaptable to a mask angle or directly to an endotracheal tube. Controlled ventilation can easily be initiated by manual compression of the reservoir bag or by attaching a Bird Mark VII Respirator directly to the end of the attachment as described by Smith. ${ }^{b}$ This system was found suitable for all patients, including paediatric patients. A smaller attachment was constructed for patients under $10 \mathrm{Kg}, 8 \mathrm{in}$. in length to which an extension could be attached. A special bag mount with pop-off valve was designed and attached to the anaesthetic machine in place of the standard Magill attachment (Figure 4). This provides a fixed position for the reservoir bag making it easily accessible for ventilating the patient with bag and mask to initiate anaesthesia and can be retained in this position during the procedure.

In place of a blow-off valve, a reservoir bag with an open tail partially occluded can be used. For paediatric cases the open tailed bag provides less resistance to exhalation. ${ }^{2}$

On occasion, it was found more convenient to attach the open tailed bag directly to the end of the attachment for both adult and paediatric cases, leaving the anaes-

-Department of Anaesthesia, University of Western Ontario, and Victoria Hospital, London. 


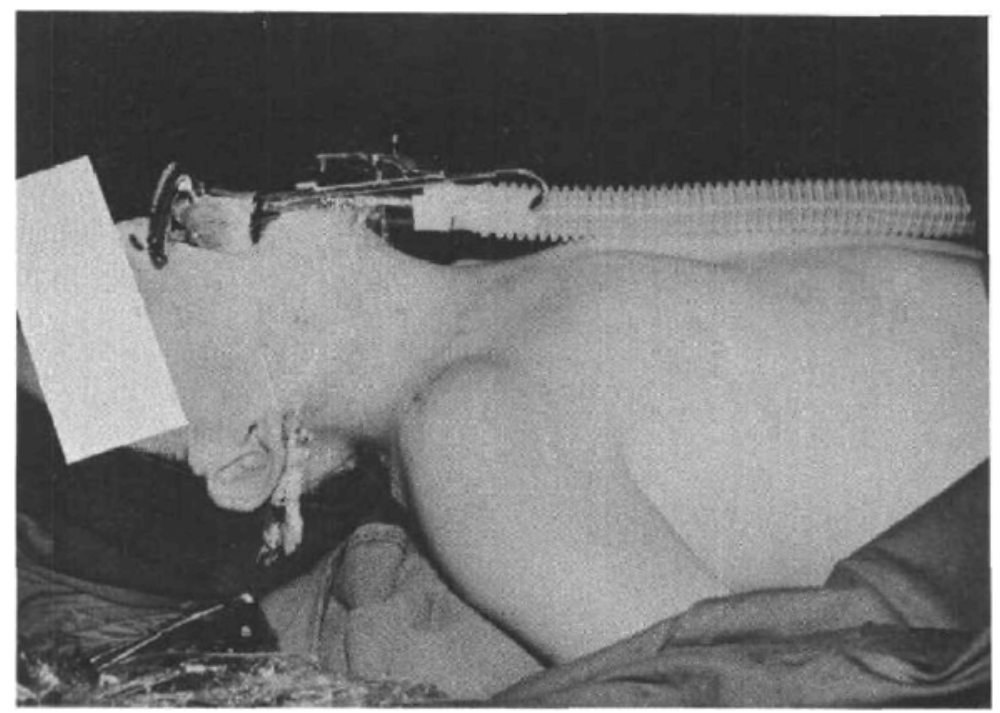

FicurB 1. Anaesthesia for repair of cleft palate.

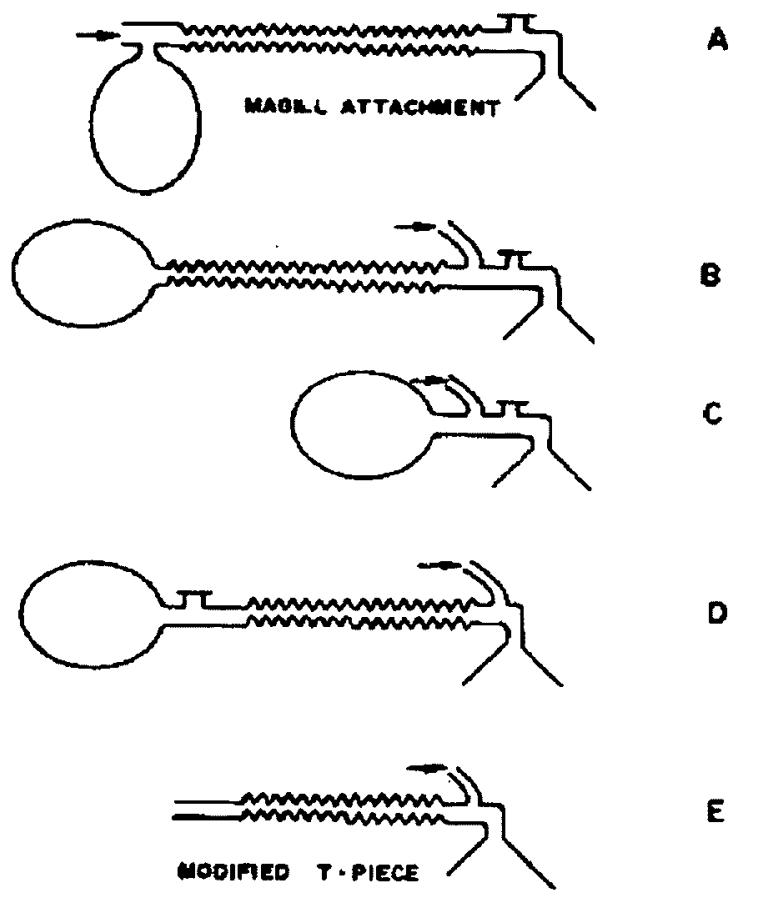

- presh gas inflom from anaesthetic machine

Figune 2. The five rebreathing systems as classified by Mapleson." 


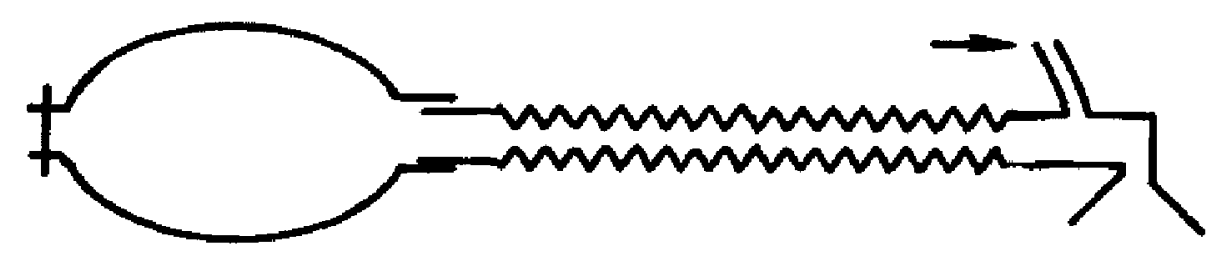

\section{FRESH GAS INFLOW FROM}

\section{ANAESTHETIC MACHINE}

Ficure 3. Paediatric system described by Rees. ${ }^{2}$

thetic machine attached only by the fresh gas inflow line remote from the operating room table (Figure 5). The length of the attachment allowed the reservoir bag to be visible and accessible under all conditions for the monitoring of respiration, for the initiation of controlled ventilation, or for pollution control of the exhaled gases into the hospital suction line.

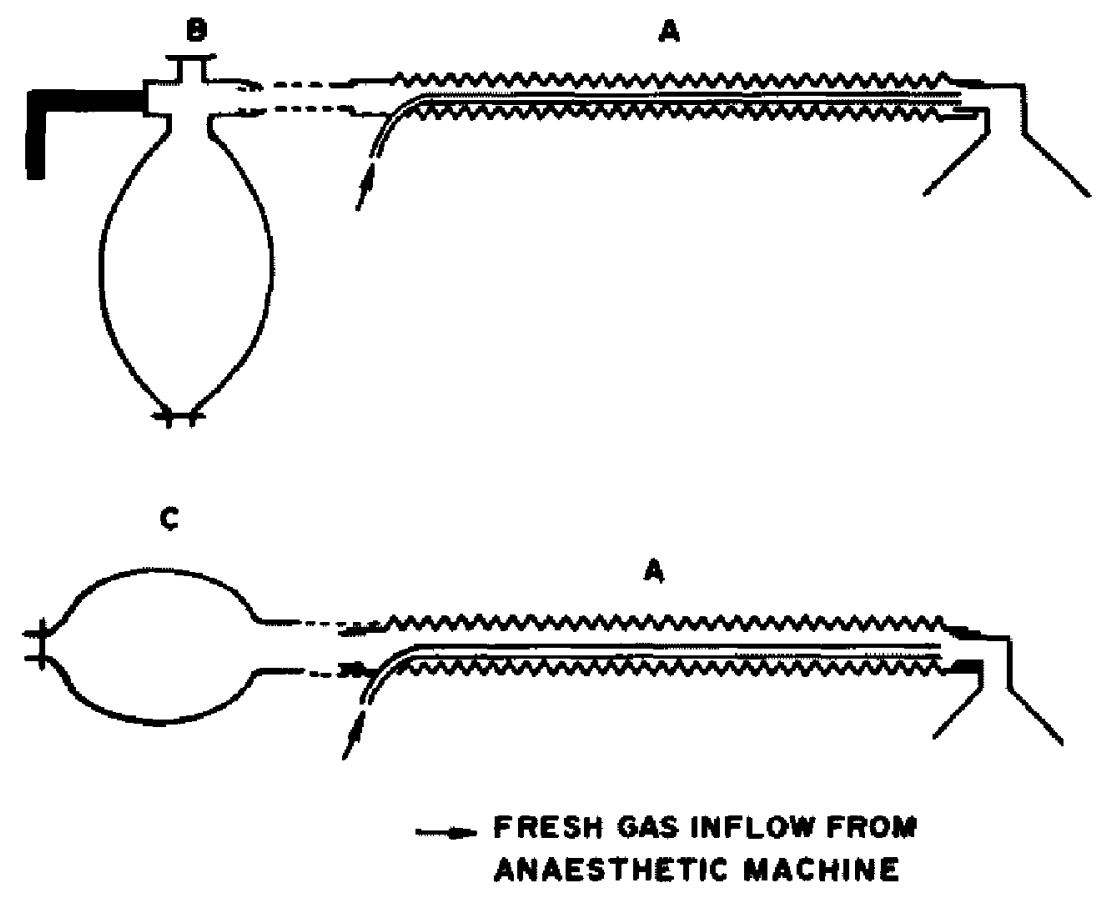

Figune 4. Modified anaesthetic system. A. Modified attachment. B. Special bag mount with pop-off valve. C. Open tailed reservair bag.

Pollution control by exhausting the exhaled gases either from the pop-off, the open-tailed bag or from the exhalation valve of the Bird Respirator can be accomplished by a simple suction arrangement (Figures $6 a$ and $6 b$ ). The exhalation at the patient's face is difficult to exhaust, as with the Magill attachment, leaving the anaesthetist and surgeon exposed to anaesthetic pollution. 


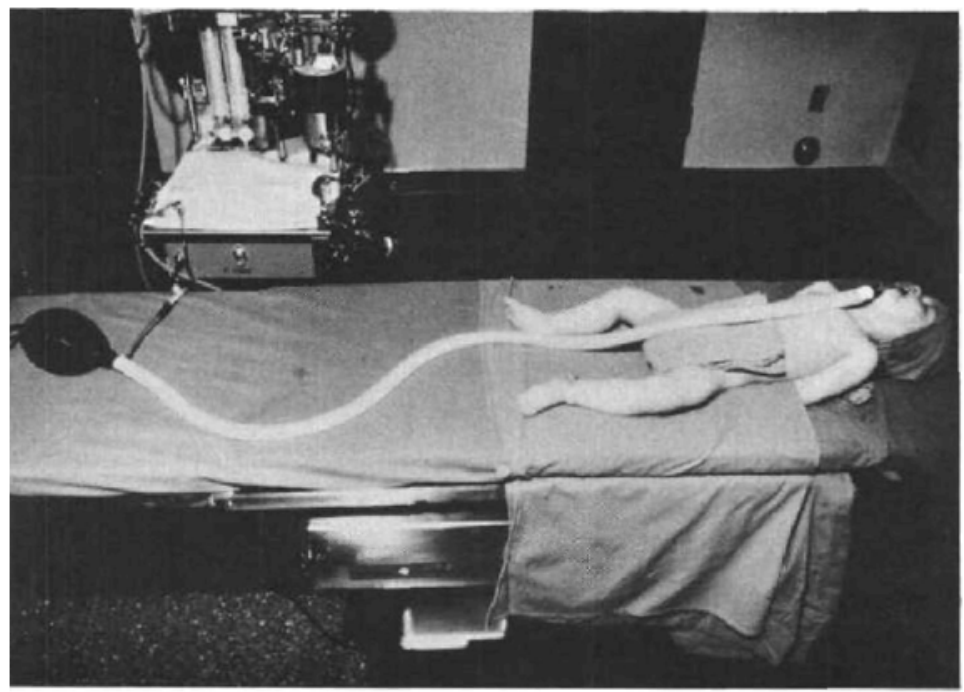

Frcure 5. Attachment remote from anaesthetic machine, attached only by inflow gas line. The open-tailed bag is attached directly to the end of the attachment.

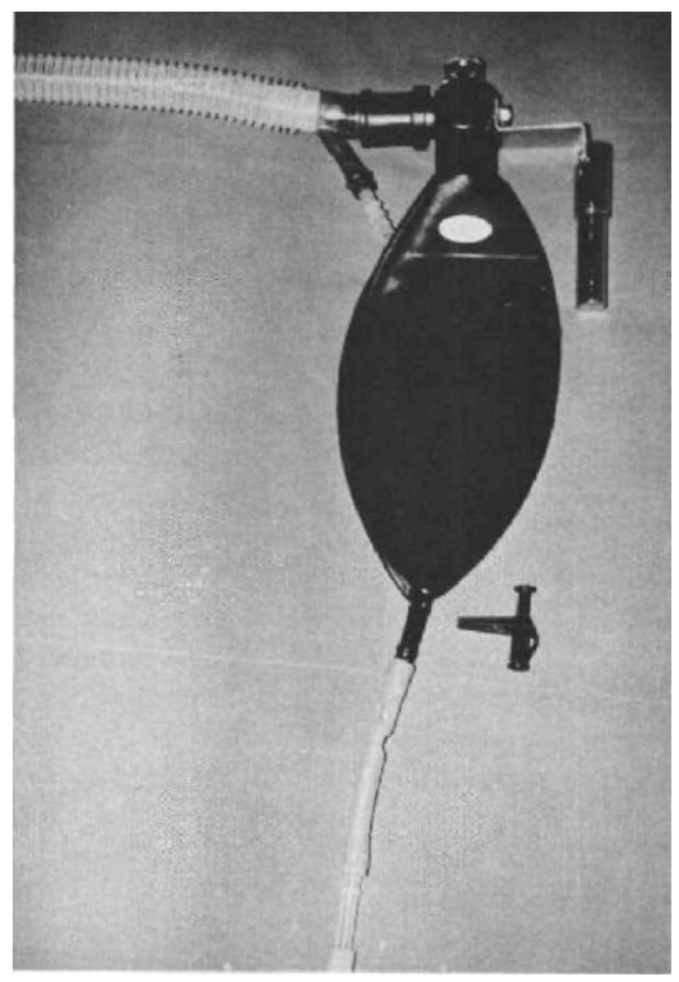

Figure $6(a)$. Pollution control by attaching hospital suction to open tailed reservoir bag. A side hole in the suction tubing must be greater than the intemal diameter of the tubing to avoid collapse of the reservoir bag. 


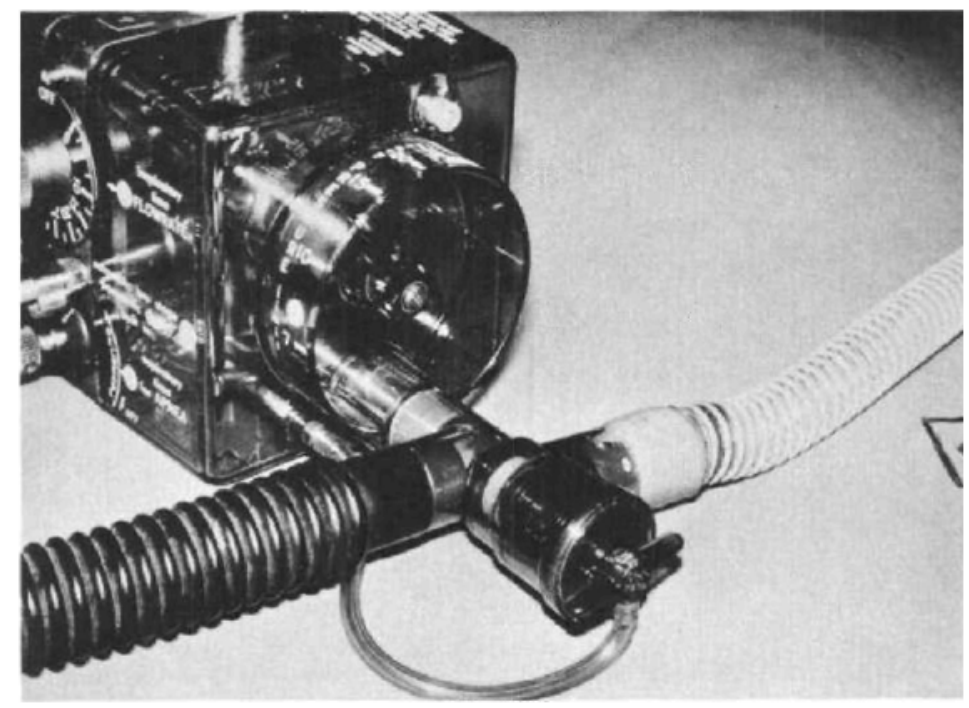

Frcuae 8(b) Pollution contral by introducing hospital suction into the reservoir tubing $(\rightarrow)$ on the exhalation valve of the Bird Respirator.

\section{Evaluation}

A clinical study was carried out at arbitrarily chosen fresh gas inflows. A fresh gas inflow of $7 \mathrm{~L} / \mathrm{min}$ was chosen as being a moderate flow acceptable to most anaesthetists. Even with circle-absorber techniques many anaesthetists are now using fresh gas inflows of 5 to 8 liters per minute. The $7 \mathrm{~L} / \mathrm{min}$ inflow consisted of $5 \mathrm{~L}$ of $\mathrm{N}_{2} \mathrm{O}$ and $2 \mathrm{~L}$ of $\mathrm{O}_{2}$. This gives approximately a 70 per cent $\mathrm{N}_{2} \mathrm{O}$ concentration, which is acceptable with intravenous narcotic anaesthesia. For comparative purposes a second fresh gas inflow of $5.5 \mathrm{~L} / \mathrm{min}$ was chosen $\left(1.5 \mathrm{~L}\right.$ of $\mathrm{O}_{2}$ and $4 \mathrm{~L}$ of $\mathrm{N}_{2} \mathrm{O}$ ). Spontaneous and controlled ventilation were evaluated at each fresh gas inflow. There was no patient selection, no standardized premedication or standardized anaesthetic agents used. For patients on controlled ventilation a Bird Mark VII Respirator was used and ventilating pressure was set to maintain mild hyperventilation. Surgical procedures included neurosurgery, cardiac surgery, abdominal surgery and all types of peripheral surgery. Following induction of anaesthesia the patients with spontaneous respiration were maintained for a period of at least 30 minutes in a state of light surgical anaesthesia and constant rates of fresh gas inflow before an arterial blood sample was taken for the measurement of blood gases. In patients on controlled ventilation the same standard was used, including an unchanged volume of ventilation for 30 minutes before blood gas determinations.

\section{Results}

The $\mathrm{PaCO}_{2}$ was determined in 26 adult patients breathing spontaneously and in 28 adult patients on controlled ventilation using the Bird Mark VII respirator. The 
fresh gas inflow related to the patients' body weights and the range of $\mathrm{PaCO}_{2}$ levels are summarized in Table $I$.

$$
\text { TABLE I }
$$

\begin{tabular}{|c|c|c|c|c|c|}
\hline No. of Patients & $\begin{array}{l}\text { Fresh Gas } \\
\text { Intlow } \\
1 / \text { min }\end{array}$ & $\begin{array}{l}\mathrm{FaCO}_{2} \\
\text { min } \mathrm{Hg}^{-} \\
\text {range }\end{array}$ & $\begin{array}{l}\text { Patlent } \\
\text { weight kg } \\
\text { range }\end{array}$ & $\begin{array}{c}\text { Fresh ge } \\
\text { mil/ks } \\
\text { overage }\end{array}$ & $\begin{array}{l}\text { ginllow } \\
\text { genge }\end{array}$ \\
\hline \multicolumn{6}{|c|}{ Sponlaneous Ventilation } \\
\hline 7 & 5.5 & $38-46$ & $52-70$ & 91.5 & $105.8-78.6$ \\
\hline 19 & 7.0 & $30-50$ & $48-8 \theta$ & 106.74 & $145,8-79.5$ \\
\hline \multicolumn{6}{|l|}{ Controlled Veritilation } \\
\hline 7 & 5.5 & $31-36$ & $52-76$ & 87.7 & $105.8-72.4$ \\
\hline 21 & 7.0 & $25-42$ & $45-84$ & 110.4 & $155.5-83.3$ \\
\hline
\end{tabular}

In plotting the individual results for spontaneous respiration against patient weight (Figure 7) it could be demonstrated that the fresh gas inflow was adequate to prevent accumulation of $\mathrm{CO}_{2}$ in the breathing system. The distribution of $\mathrm{PaCO}_{2}$ values throughout the range of body weights would seem to indicate that the mild elevation of $\mathrm{PaCO}_{2}$ observed was due to drug induced respiratory depression and not dependent on the volume of fresh gas introduced into the breathing system.

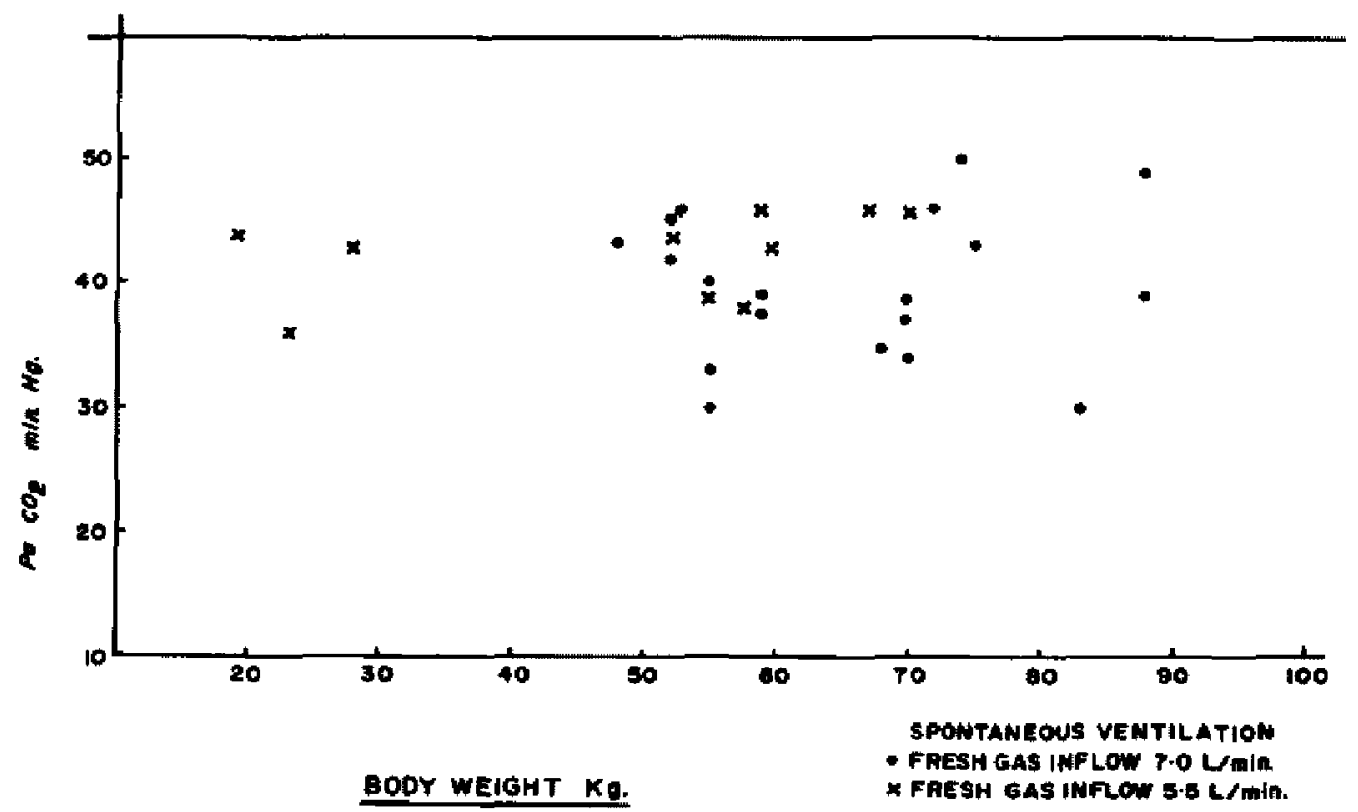

Ficune $7 . \mathrm{PaCO}_{2} \mathrm{mmHg}$ related to body weight $\mathrm{Kg}$ in patients breathing spontancously. 


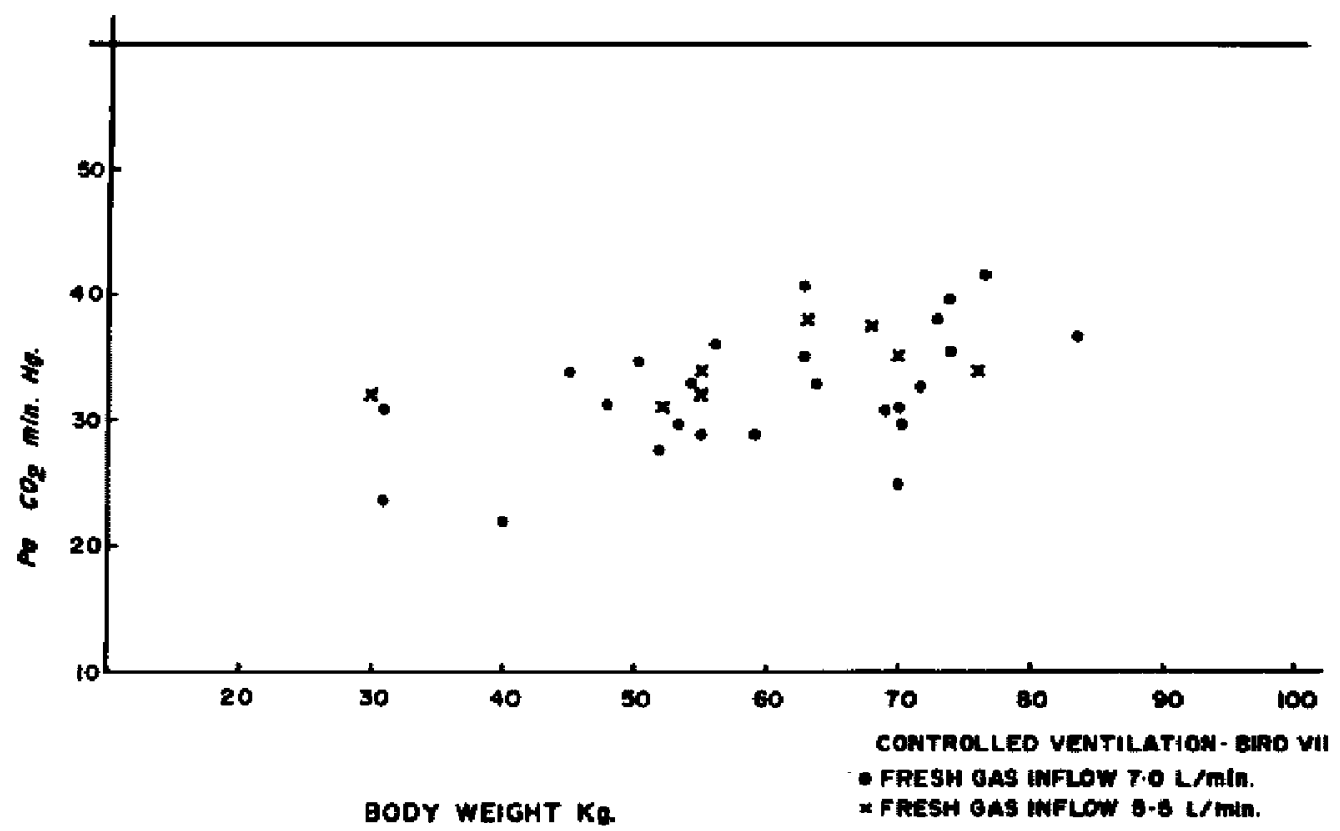

Figure $8, \mathrm{PaCO}_{2} \mathrm{mmHg}$ related to body weight $\mathrm{Kg}$ in patients on controlled ventilation.

With controlled ventilation, there was a definite positive correlation between $\mathrm{PaCO}_{2}$ and body weight (Figure 8 ) for a given volume of fresh gas inflow. As long as the volume of ventilation exceeds the ventilatory requirements and is in excess of the fresh gas inflow, the $\mathrm{CO}_{2}$ elimination depends on $\mathrm{CO}_{2}$ production and the rate of fresh gas inflow. Since the latter was fixed, it can be expected that the greater volume of $\mathrm{CO}_{2}$ produced by larger patients would result in a higher $\mathrm{PaCO}_{2}$.

The volume of the breathing attachment described exceeded the tidal volume of the patient in every instance. However, it was found that the volume of the breathing system did not appear to influence the arterial $\mathrm{CO}_{2}$ level.

\section{Discussion}

For patients breathing spontaneously under anaesthesia the Magill attachment or Mapleson A system is the most widely used semiclosed single limb anaesthetic system. Kain and Nunn ${ }^{6}$ found for the Magill system, with patients breathing spontaneously, that the mean value for the ratio of minimum adequate fresh gas inflow to minute volume was $0.7 \mathrm{I}$ before rebreathing occurred. This observation is in agreement with Mapleson. ${ }^{5,7}$ They also noted that the customary fresh gas inflow rates with this system are in excess of the requirements and that the actually required adequate fresh gas inflow rate is of the same order as the inflow rates used by many anaesthetists for circle absorption circuits. The Magill system is unsatisfactory during artificial ventilation ${ }^{8.9}$ and its use is therefore confined to situations in which adequate spontaneous respiration can be maintained throughout the operation. 
For patients who are being ventilated, Waters and Mapleson ${ }^{B}$ have shown that the Mapleson D system involves less rebreathing than the Mapleson A system (Magill attachment). Harrison ${ }^{10,11}$ reviewed the modifications of the Ayre's T-piece and concluded that a fresh gas inflow of $2 \%$ to 3 times the minute volume was required. However, Nightingale et al. ${ }^{4}$ pointed out that in most of the reported work pertaining to the $T$-piece systems, emphasis had been placed upon the prevention of rebreathing rather than the retention of carbon dioxide by the patient. Their work demonstrated that with manually controlled ventilation this goal could be achieved easily despite the occurrence of "considerable rebreathing". They consequently concluded that, with controlled ventilation, a fresh gas inflow of 220 $\mathrm{ml} / \mathrm{Kg}$ body weight per minute was sufficient to prevent carbon dioxide retention, on the basis of minute volume, airway pressure and inspired and end-expired carbon dioxide concentrations.

Controlled ventilation can be carried out by attaching the distal end of the single breathing tube to the patient outlet of the respiratory valve of the Bird respirator as described by Smith. ${ }^{3} \mathrm{~A}$ negative pressure as recommended by $\mathrm{Smith}^{\mathbf{3}}$ is not necessary in our opinion. Air dilution of the anaesthctic mixture is virtually absent as long as the volume of the breathing attachment exceeds the patients' tidal volume. The $\mathrm{CO}_{2}$ elimination is dependent on the frcsh gas inflow as long as the volume of ventilation is below the volume of the attachment plus the patient's required tidal volume, i.e. approximately $1000 \mathrm{ml}$ with the attachment described (attachment volume $500 \mathrm{ml}+$ tidal volume $500 \mathrm{ml}$ ). Only with the rather large tidal volumes, dilution of the anaesthetic gases and further removal of the $\mathrm{CO}_{2}$ would occur.

The system described is found to be ideal for anacsthosia for both paediatric

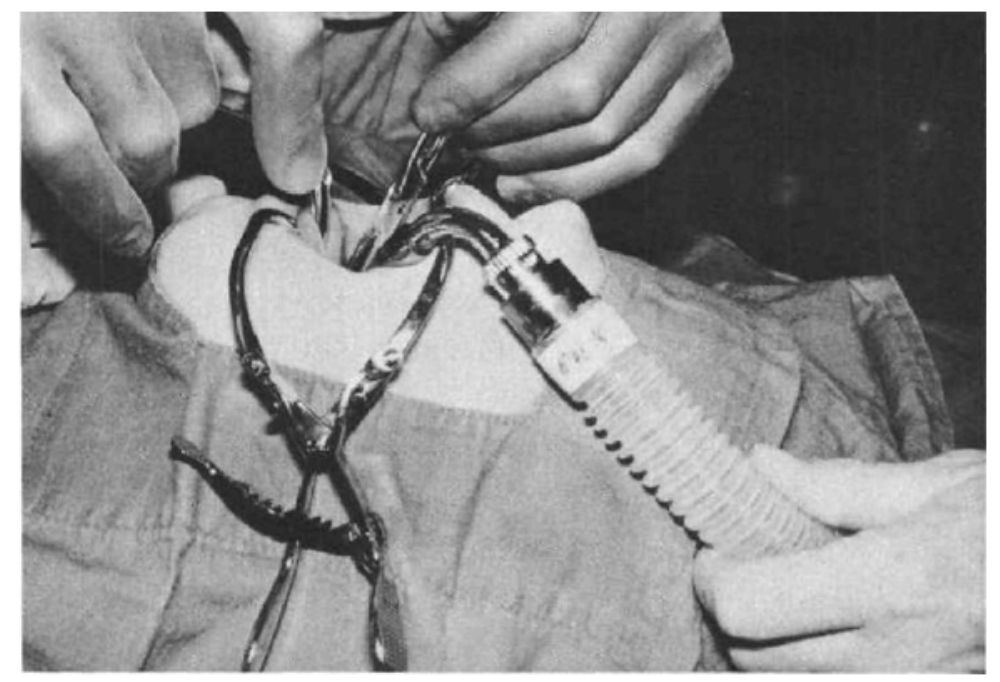

Frgure 9. Anaesthesia for tonsillectomy in a child. 
TABLE II

Advaniages of The Descalaed Crrcuit OVer THe Circle System
1. Single tube to patient
2. Light weight
3. All valves can be eliminated from the system
4. Useful in all age groups
5. No carbon dioxide absorption required
6. Circuit easily sterilized
7. Adaptable to all types of anaesthetic procedures
8. Ideal for head and neck procedures

and adult tonsillectomy (Figure 9) where the anaesthetist is placed at the head of the operating room table. Non-rebreathing valves or pop-off valves in this situation are bulky and add weight to the system. It is the preferred system for cerebral angiography in our hospital, where other systems have been found awkward to adequately secure in place without drag which pulls the head out of position, be removed from the $\mathrm{X}$-ray field and permit mechanical ventilation. Patients undergoing surgical procedures exceeding one hour are usually ventilated mechanically. This system then becomes a more efficient system than the Mapleson A system. The system as described has been found adaptable to paediatric anaesthesia, requiring only the addition of a paediatric face mask and smaller reservoir bag. The incorporation of an open-tailed reservoir bag into the system removed all valves which add resistance to the system (Table II). The attachment provided improved conditions for the surgeon when compared to conventionally used circuits, particularly in procedures on the head, face and neck. In contrast to breathing attachments previously used and especially for plastic surgery on the face, the anaesthetist can now control the patients ventilatory requirements while well removed from the surgical field.

This system has been clinically evaluated in over 500 cases for all ages of patients and types of surgical and diagnostic procedures and has provided uniformly satisfactory anaesthetic conditions at the fresh gas inflow rates described. A fresh gas inflow of $7 \mathrm{~L} / \mathrm{min}$ appeared to be sufficient to prevent $\mathrm{CO}_{2}$ retention with this system in all adult patients.

If a bellows type ventilator is used where admixture of air or oxygen cannot occur (e.g. Bird Mark IV or Air Shields Ventilator-Ventimeter) $\mathrm{CO}_{2}$ elimination would depend entirely on the gas inflow. It would be possible, therefore, to vary $\mathrm{PaCO}_{2}$ and ventilating volume independently of each other, as long as the ventilating volume exceeds the volume of fresh gas inflow. In certain anaesthetic procedures it is desirable either to elevate or to decrease the level of $\mathrm{CO}_{2}$. Manipulation of the fresh gas inflow would appear simpler and more predictable than the addition of dead space or changes in the ventilating volume.

It is planned to carry out further studies to evaluate the use of the attachment as a replacement for the circle breathing system and to obtain more precise data on the relationship between fresh gas inflow, $\mathrm{CO}_{2}$ elimination and rebreathing- 


\section{SUMMARY}

A streamlined modification of the combined Mapleson $D \& E$ systems has been described. The main advantages of this circuit are that it is light in weight, adaptable to both adult and paediatric anaesthesia, allows complete airway control at all times, and permits the institution of positive pressure ventilation. The circuit is easily adaptable for pollution control.

A clinical study of the circuit was carried out with fresh gas inflows of $5.5 \mathrm{~L} / \mathrm{min}$ and $7 \mathrm{~L} / \mathrm{min}$. $\mathrm{PaCO}_{2}$ was within an acceptable range with either spontaneous or controlled ventilation, indicating adequate carbon dioxide elimination at these inflow rates.

The circuit has been evaluated in over 500 cases and was found satisfactory for all types of surgery. It was especially advantageous in surgery of the head and neck.

\section{RÉSUMÉ}

Nous avons décrit une modification des systèmes combinés de ventilation anesthésique, Mapleson D et E. Les principaux avantages de ce circuit sont qu'il est leger, applicable aussi bien aux adultes qu'aux enfants, permettant, en tout temps, un contrôle entier des voies respiratoires et l'installation d'une ventilation à pression positive. On peut facilement adapter le circuit aux mesures anti-pollution.

Nous avons fait une étude clinique de ce circuit en employant un apport de gaz frais de 5.5 litres et de 7 litres par minute. $\mathrm{La}^{\mathrm{PaCO}_{2}}$ est demeurée dans les limites acceptables aussi bien avec la ventilation spontanée qu'avec la ventilation contrólée, démontrant que, à de tels débits, l'élimination du $\mathrm{CO}_{2}$ était adéquate.

Nous avons étudié ce circuit chez plus de 500 malades, et il s'est avéré satisfaisant pour toutes les sortes de chirurgie. C'est dans la chirurgie de la tête et du cou qu'il nous a semblé plus avantageux.

\section{REFERENCES}

1. Waters, D.J. A composite semi-closed anaesthetic system suitable for controlled or spontaneous respiration. Brit. J. Anaesth., 33: 417 ( 1961 ).

2. ReEs, G.J. Anaesthesia in the newborn. Brit. Med. J., 2: 1419 ( 1950 ).

3. Smrre, C. Controlled ventilation employing a modified Ayre's technic. Anaesth. and Analg., 44: 842 (1965).

4. Nightingale, D.A., Richanos, C.R., \& Glass, A. An evaluation of rebreathing in a modified $T$-piece system during controlled ventilation of anaesthetized children. Brit. J. Anaesth, 37: 762 (1965).

5. Mafleson, W.W. The elimination of rebreathing in various semi-closed anaesthetic systems. Brit. J. Anaesth., 26:323 (1954).

6. Kan, M.L. \& Nonn, J.F. Fresh gas economics of the Magill circuit. Anaesthesiology, 29; $964(1968)$.

7. Mafleson, W.W. Theoretical consideration of the effects of rebreathing in two semi-closed anaesthetic systems, Brit. Med. Bull. 14: 64 (1958).

8. WATERs, D.J. \& MApleson, W.W. Rebreathing during controlled respiration with various semiclosed anaesthetic systems. Brit. I. Anaesth., 33: 374 (1961).

9. Sxкes, M.K. Rebreathing during controlled respiration with the Magill attachment. Brit, J. Anaesth., $31: 247$ (1959).

10. Harnison, G.A. Ayfe's T-piece: A review of its modifications. Brit. J. Anaesth., 36: 115 (1964).

11. Harrison, G.A. The effect of the respiratory flow pattem on rebreathing in the $T$-piece system. Brit. J. Anaesth., 36: 206 (1964).

12. Spoenel, W.E. \& McFarlane, R.M. Anesthetic technics for operating about the face. Anesth. and Analg., 45: 170-175 (1966). 